\title{
Brasil: uma Interpretação Histórica
}

DoDE-SE definir tôda a história do Brasil dizendo que ela se passa sob 1 o signo do movtmento. As terras brasileiras surgem para a civilização ocidental nessa época de efervescência de espírito, isto é, de movimento, que foi a Renascença; e surgem no interior de um processo de movimento, que era a expansão marítima dos Portuguêses. As primeiras cenas brasileiras são, igualmente, cenas de movimento: o desembarque, as patrulhas de reconhecimento, a primeira missa, que os indígenas, segundo a célebre Carta de Pero Vaz de Caminha, acompanham piedosamente, imitando todos os gestos efetuados pelo Homem Branco. No primeiro século, quando o destino da nova terra se jogava nas mãos dos piratas como os dados sôbre a túnica, o tráfico da madeira preciosa era, ainda, um comércio fundado essencialmente sôbre o movimento; mais tarde, nos séculos 17 e I8, foi pelo movimento, pela marcha ininterrupta através da floresta desconhecida, que o território começou a adquirir o que seria, afinal, a sua fisionomia geográfica definitiva. Essa marcha foi, em certo sentido, um gesto deliberado contra o ato diplomático que, por um instante, acreditou poder interromper o movimento da história: com efeito, seis anos antes da Descoberta, em I494, o Tratado de Tordesilhas, obra de diplomatas idosos e sentados, procurava quebrar o princípio dinâmico que era o das navegações pelo princípio estático de uma geografia essencialmente medieval, essa geografia sedentária que, impregnada de teologia, pensou, por um momento, negar os mundos novos que, de tôda evidência, começavam a surgir.

$O$ Tratado de Tordesilhas, fundado na idéia do que se poderia chamar uma cosmografia imaginária, fixava uma linha a oeste da qual tôdas as novas terras que por acaso surgissem seriam espanholas, e a leste da qual tudo seria português. "This line", escreve o Professor C. R. Boxer.

was a meridian drawn 370 leagues to the west of the most westerly of the Cape Verde Islands; but for more than two and a half 
centuries there was no agreement between the two Iberian powers as to where this line ran between the Amazon and the Rio de la Plata. By 1746 the rulers at Lisbon and Madrid had belatedly come to realize the need for negotiating a boundary settlement which would take account of what had happened in South America and in the Far East during the last two hundred and fifty years..." 1

O que acontecera, nesses duzentos e cinqüenta anos, foi simplesmente que a história brasileira ignorara o Tratado de Tordesilhas e, arrastada por seu impulso próprio, continuou o movimento que impelira as caravelas portuguêsas das costas africanas para o centro misterioso de atração que se encontrava do outro lado do oceano. Entre 1534, data $\mathrm{cm}$ que, com os primeiros engenhos, inicia-se verdadeiramente o que se poderia chamar a "civilização brasileira", e I750, data do Tratado de Madrid, que legitimava oficialmente todos os desrespeitos ao Tratado de Tordesilhas, é, justamente, a nação brasileira que se constitui, scmpre através do movimento, que é a sua constante essencial. Esse movimento foi, antes de mais nada, uma conquista territorial. Se é verdade que, no primeiro século, os Portuguêses pareciam temer a amplitude da tarefa que os esperava e contentavam-se, como diria Frei Vicente do Salvador, o primeiro historiador brasileiro, "de andar arranhando ao longo do mar como caranguejos", também é certo que os séculos 17 e I8 assistiriam a uma ocupação sistemática do território, a tal ponto que, por volta de I.750, as fronteiras do Brasil já são, em substância, as suas fronteiras definitivas. "Quando se pensa", observa o Professor Fernando de Azevedo,

nos obstáculos de tôda ordem que tinham de vencer os sertanejos, à frente de suas tropas e boiadas, e os bandeirantes, nas suas entradas pelo sertão, à caça do índio ou à procura dos terrenos auríferos, não se pode deixar de reconhecer, neste movimento estupendo de expansão territorial, as fundações robustas em que, no interior, começou a erguer-se a estrutura da nação. A tomada de posse, pelo homem, do meio geográfico, eriçado de florestas virgens, amuralhado de montanhas, embolado nos espigões, apaulado nos pantanais e recortado de rios imensos que se irradiam e se cruzam em quase todos os sentidos, para o mar e terra a dentro, é uma epopéia

1 C. R. Boxer. The Golden Age of Brazil. 1695-1750. Growing pains of a Colonial Society. Berkeley and Los Angeles: The University of California Press, 1962, p. 292. 
selvagem em que irrompeu, com tôda grandeza do esfôrço humano e no quadro imenso dos labôres, das penas e dos sacrifícios, "uma das afimações vivas e autênticas do sangue brasileiro nas ásperas terras" que conduziam às pastagens e às cidades, ao litoral e à mineração, nos fluxos e refluxos das vagas sertanejas. Certamente, no fundo do quadro, formigava a escravaria negra, nas terras da mineração, sôbre o leito dos rios ou ao pé das montanhas, ou se agitava a massa dos silvícolas que, escravizados em cada uma das expedições, desciam aos milhares de cada vez, para serem distribuídos ou vendidos a baixo preço nas cidades e vilas do litoral. Mas as origens de todos os povos são dolorosas e sangrentas (já Augzisto Comte falava "na ferocidade das pátrias primitivas".); e a) provações e sofrimentos das raças que o conquistador branco e os desbravadores dos sertões se viram na necessidade de escravizar e que ota opunham bravia resistência ora cediam à dura imposição, não devem fazer-nos esquecer as angústias e os reveces dos sertanejos e bandeirantes, que traziam o sangue autóctone nas veias e que, conduzindo o gado ou marchando em expediçōes, vadeando rios, escalando serranias e embrenhando-se pelas florestas, dilatavam as fronteiras do país e conquistavam o interior à civilização. Este fenômeno a que Trmwer chamou "deslocação de fronteiras", * para significar a expansão econômica territorial de um país, dentro de seus limites políticos, e que ainda se está processando no Brasil, foi, como observa $J . F$. Normano, o movimento verdadeiramente formador da nação..."2

Fernando de Azevedo acentua ainda que, conforme Roy Nash apontara anteriormente, hả uma diferença fundamental.

cntre a expansão territorial na América do Norte, regular, ordenada e contínua, numa só direção e acompanhada quase sempre de progressiva colonização interna, e a expansão geográfica no Brasil, irregular, desordenada, realizada em quase tôdas as direções, sem un desenvolvimento econômico paralelo ou simultâneo. ${ }^{3}$

Podemos acrescentar que, se a história norte-americana foi, nessas perspectivas, uma história de movimento, a história brasileira é também uma

* F. J. Tutner. The Frontier in American History. New York, 1926, p. II (nota de Fernando de Azevedo).

2 Fernando de Azevedo, A Cultura Brasileira, 3a. cd., tomo 1, p. 87. São Paule: Melhoramentes, 1958.

is Op. cit., p. 88. 
história de movimentação. Com efeito, mais do que a irregularidade e a desordem, o que caracteriza o movimento na história do Brasil, é a sua simultaneidade. E aqui reside, segundo penso, a maior divergência entre os movimentos de fronteiras nos dois países. Se os Estados Unidos movimentam-se exclusivamente no espaço e num espaço linear, aberto, desembaraçado, no qual o único obstáculo sério é o próprio homem, o Brasil movimenta-se igualmente no tempo. A dimensão temporal é, com efeito, a singularidade histórica brasileira. Irrompendo bruscamente da idade da pedra lascada para a civilização da Renascença, o Brasil viu-se obrigado, desde o seu primeiro dia, a transformar a sua história numa corrida contra o relógio. As fronteiras territoriais foram, assim, atacadas ao mesmo tempo que as fronteiras sociais e políticas; a dimensão geográfica só adquiria sentido quando acompanhada da dimensão econômica. Por outro lado, o impulso irresistível do movimento criaria o que nenhum outro país sul-americano chegaria a criar, isto é, um território imenso, no qual todos os climas são possíveis, tôdas as formas de atividade, todos os tipos de geografia humana. Por isso mesmo, se, no espaço, a histótia do Brasil é uma história de movimento, no tempo ela é uma história de ciclos; mas também no tempo ela é uma história de movimento, visto que os ciclos se sucedem em regiões diferentes, da mesma maneira por que ela setá, no espaço, uma história de ciclos, já que é sob a forma de atividades rotativas que a implantação geográfica se manifesta. De acôrdo com o Professor Reynold E. Carlson,

the history of Brazil's economy is characterized by six cycles, each of which followed a similar pattern. Each cycle centered around a particular commodity in which - at the height of the cycleBrazil occupied the leading position in world production and subsequently declined as a result of competition from other producing areas. The first of these cycles may be roughly dated from I 500 to I550, during which period the cutting and exportation of dyewood (Pau Brasil) constituted the entire economic basis of the colony. The region in which this activity took place was bounded on the north by Cabo São Roque (Rio Grande do Norte) and on the south by Cabo Frio (Rio de Janeiro), although the most intense exploitation was in the coastal area from Pernambuco to the souther edge of what is now Sergipe. ... The sugar-cane cycle ran for approximately a century, from 1600 to 1700 , and production was located in the northeast region, largely in the states of Pernambuco and Bahia. ... The discovery of gold in $I 690$ precipitated a third 
cycle lasted to about $1770 .$. The period of domination of the gold cycle was overlapped by the diamond rush that occurred about I730 and excited a new wave of migration into the interior, especially to Minas Gerais. ... The decline of the sugar cycle was accompanied by the rise of cotton production in the states of Bahia, Pernambuco, Ceará and Maranhão, although the chief area of production was along the margins of Alagoas, Pernambuco, and $\mathrm{Pa}$ raiba. ... The rubber cycle may be dated from about 1860 to I9ro, a period in which Brazil had a virtual monopoly as a supplier in the world market. The business of extracting rubber was centered in the Amazon region, where the lack of transportation facilities and the acute labor shortage were serious handicaps to the expansion of production for a world market that was practically unlimited. ... Perhaps the most famous and important of the economic cycles is the cultivation of coffee which, for more than a century, has been the keystone of the economic structure of Brazil. The coffee cycle began about 1830 and has been concentrated in the states of São Paulo, Rio de Janeiro, Minas Gerais, and Espírito Santo, a'though in recent decades Paraná has also emerged as a sizable producer..." 4

Como se vê, a economia brasileira é uma economia em movimento, não sòmente no sentido vertical, como, em regra, a dos demais países, mas ainda, e sobretudo, no sentido horizontal. Sob êsse aspecto, não deixa de ter um certo sabor o fato de o café se haver identificado tão intimamente com o Brasil que se tornou, não apenas no sentido figurado, mas no próprio, o símbolo da agricultura brasileira. E que o café se distingue por ser, como todos sabem, uma planta eminentemente itinerante. Do Vale do Paraíba, no Estado do Rio e São Paulo, êle se deslocou para o sul do país, no Estado do Paraná, onde se encontram as últimas terras brasileiras apropriadas a êsse tipo de cultura. $\mathrm{Na}$ verdade, embora o fato ainda não tenha passado para todos os espíritos, pode-se afirmar que, do ponto de vista histórico, e, mesmo do ponto de vista econômico, o ciclo do café já terminou. Se há alguma esperança para o Brasil, ela estará, por um lado, nas possibilidades do nôvo ciclo que agora se inicia, o ciclo da industrialização, e, por outro lado, na conquista de uma organicidade tal que substitua o ritmo desastrosamente sucessivo de todos êsses

4 Cf. Reynold E. Carlson, capítulo sôbre a economia, in T. Lynn Smith \& Alexander Marchant. Brazil: Portrait of Half a Continlent New York: Dryden, 1951, pp. 226 e seguintes. 
ciclos por uma economia diferenciada e múltipla. Isso corresponderá, sem dúvida, à rejeição parcial da regra que tem caracterizado a história brasileira, mas, tanto quanto se pode prever, é o único meio de responder ao desafio de um mundo que, agora mais do que nunca, caracteriza-se por sua complexidade.

O denominador comum de todos êsses ciclos, entre 1550 e 1888 , foi o escravo e, depois da Abolição, o imigrante estrangeito. $O$ único ciclo que se fundou exclusivamente no trabalhador nativo parece ter sido o da borracha; ainda assim, ao movimento do mercado do trabalho, que ia buscar os seus elementos, primeiro na Āfrica e, depois, na Europa, junta-se o movimento dos trabalhadores nordestinos que partiam para a Amazônia e o nomadismo das populações locais, tudo isso reunido em tôrno de uma cultura eminentemente peripatética como é a da borracha. Ora, através do escravo e do imigrante penetramos em cheio na história do Brasil tomada em seu sentido político mais imediato: foi o escravo que assegurou o sucesso dos ciclos do açúcar, do ouro, do al'godão, e do café, na sua primeira fase; o imigrante garantirá o desenvolvimento da lavoura cafeeira e está nas fontes mesmo do processo de industrialização. Em menos de um século, desde a Abolição, o Brasil está tentando, com o trabalho livre, conquistar o seu lugar na civilização do Ocidente; nos três séculos anteriores, com o escravo, êle garantiu, antes de mais nada, os seus fundamentos geográficos, a posse incontestada do território. Com efeito, o Tratado de 1750 foi, em sua essência, o reconhecimento do princípio que depois se tornou essencial na história diplomática do Brasil, o princípio do uti prossidetis, ou seja, a legitimação de todo direito que se fundasse sôbre a posse efetiva do território. Assim, não apenas o Brasil foi um tesultado do movimento que impulsionou os Portuguêses à Descoberta, e, mais tarde, à expansão geográfica, como, ainda, ficour devendo ao movimento, no espaço e no tempo, a fixação definitiva das suas fronteiras entre as nações americanas.

As fronteiras brasileiras começaram por ser econômicas para terminar por ser políticas, ao contrário das norte-americanas que começatam por ser políticas para terminarem por ser econômicas. Da economia para a política, a história do Brasil e, igualmente, a história de um movimento de consciência, a consciência de nação, que, com a Independência, transformar-se-ia em consciência de nacionalidade. Algumas datas podem fixar as etapas dêsse processo. Sòmente trinta anos depois da descoberta, em 1532, é que o Govêrno Português, alarmado com o perigo dos piratas franceses, decidiu iniciar a ocupação efetiva do território. Assim se inicia também, com as capitanias hereditárias, a nossa história política. Mas, essa 
experiência, que partilhava entre quinze grandes senhores a totalidade do território, constituiu

em última análise, uma experiência feudal, nìtidamente marcada pelo elemento essencial nesse regime que se caracterizava, no feudalismo europeu, pela distribuição e posse da terra, como um meio de fixar o homem, suscitar a sua defesa e o interêsse pela colonização. ${ }^{5}$

Ora, reinstituir o feudalismo no primeiro têrço do século I 6 já era, políticamente, um anacronismo; os fatos, como seria de esperar, mostratam-se mais fortes e, já em 1549, criava-se o Govêrno Geral do Brasil, com sede na Bahia. No mesmo momento, começam a chegar ao país os primeiros escravos; logo em seguida, inicia-se, na região nordestina, a esplêndida "civilização do açúcat" cujo declínio seria acompanhado, em I763, pela transferência do Govêrno Geral para o Rio de Janeiro e simultânea elevação do pôsto de Governador Geral para o de Vice-rei. O ciclo do ouro inscreve-se nesse processo político; assim, a mesma lei do movimento mais uma vez se manifesta e, juntamente com o centro de gravidade da economia, é o centro de gravidade da política que se desloca.

Simultâneamente, nos séculos $\mathrm{r} 7 \mathrm{e}$ I8, as Bandeiras haviam iniciado - processo de conquista territorial. Essas expedições, escreve ainda o Professor Fernando de Azevedo,

abrindo com as armas o caminho por onde as bandeiras e, depois o gado e as tropas, continuavam a avançar, desbravando o interior, dilataram os limites políticos e levaram mais perto dêles o desenvolvimento econômico. ${ }^{6}$

A expansão geográfica estava tão ìntimamente ligada com a ambição mineradora que é realmente impossivel distingui-las; pode-se dizer que, partindo em busca de minas auriferas e de pedras preciosas, os Bandeirantes fincavam, ao mesmo tempo, os marcos das novas fronteiras que o poder central vinha, em seguida, ocupar. A mudança do Govêrno Geral para o Rio de Janeiro é, ao mesmo tempo, o reconhecimento e a aceitação dum fenômeno importante na vida brasileira: o deslocamento do centro de civilização para o sul do país. Juntamente com o declínio da atividade mineradora começa a história do café; paralelamente a um e outra, o pensamento político penetra no país.

5 Fernando de Azevedo, op. cit., p. 149.

6 Op. cit., p. 88 , nota 9. 
Com efeito, não é sem razão que partiram de Minas Gerais no fim do século I8 as primeiras manifestações concretas de rebelião contra a Coroa; não é sem razão, tampouco, que a independência do Brasil foi proclamada no Estado de São Paulo. A independência política é um processo que amadurece lentamente. Ainda aqui, por conseqüência, estamos em face de um movimento. Movimento no tempo que, à sua maneira, protestava e reagia contra o fato de Portugal haver conservado o Brasil, por assim dizer, fora da história ocidental; movimento no espaço porque foi da implantação territorial e, em particular, da exploração mineradora que nasceu o sentimento de uma personalidade nacional diferente da metropolitana. Esse fenômeno era assinalado, já em I727, por Antônio Rodrigues da Costa, um dos conselheiros da Coroa Portuguêsa: "É óbvio", dizia êle, que "se o Brasil fôr colocado num dos pratos da balança e Portugal no outro, o primeiro pesará mais do que o último e, conseqüentemente, o maior e mais rico não consentirá em ser governado pelo menor e mais pobre". O Professor C. R. Boxer, que cita essas palavras proféticas, acrescenta que

the break did not come for another ninety years, but the foundations of Brazilian independence were laid willy-nilly by the Portuguese government during the reign of Dom João V.7

Entre a morte de $\mathrm{D}$. João $\mathrm{V}$ e a proclamação da independência, passamse setenta e dois anos de grande efervescência política: por um lado, a Metrópole, apesar da "ditadura esclarecida" do Marquês de Pombal, inicia o processo de declínio em que deixará de ser uma grande potência; por outro lado, as idéias da Ilustração francesa repercutem na Colônia americana e, conforme ficou dito, introduzem ali, pela primeira vez, o que se poderia chamar um pensamento político. A revolução colonial de I 789 foi ràpidamente sufocada; de resto, não chegou a ser uma revolução e foi apenas uma revolta. Mas, deixou um germe, que circunstâncias políticas absolutamente estranhas e imprevisiveis concorreriam para fortalecer.

É que, por um dêsses paradoxos em que a História é costumeira, os verdadeiros resultados da Ilustração francesa, quero dizer, o govêrno de "liberdade, igualdade, fraternidade", seria instituído, não na França, mas nos Estados Unidos; enquanto isso, o produto final e o subproduto da Revolução Francesa chama-se Napoleão Bonaparte. Ora, Bonaparte, decretando o bloqueio da Inglaterra, encontrou inesperadamente a maior resistência por parte da nação européia mais fraca (Portugal) : se, como já se

7 Boxer, op. cit., p. 325. 
disse, a Inglaterra foi o único país do mundo que cometeu o ridículo de vencer Napoleão, é justo pensar que Portugal a ajudou bastante. Contudo, D. João VI, rei de Portugal, não poderia vencer Napoleão senão pela fuga: a fuga da Família Imperial para o Brasil, em. I807, funda definitivamente um grande império americano e consolida a independência que se desenvolvia obscuramente nas consciências. Esse episódio histórico é um daqueles acontecimentos que vêm envoltos em grotesco e grandeza ao mesmo tempo; a própria figura de D. João VI, a sua vida de família, as medidas políticas e administrativas que tomou, tudo isso é uma espécie de gigantesco "vaudeville" em que não se sabe muito bem quais são as verdadeiras intenções do autor. O historiador brasileiro Oliveira Lima já demonstrou, entretanto, num livro definitivo, que as aparências de ridículo, nesse rei gotoso e glutão que fugia da Europa com um bando de parasitas, eram profundamente enganadoras e que êle lançou realmente as fundações da independência de uma nação cuja grandeza pressentia. A verdade é que, quando D. João VI regressa para a Europa, em $\mathrm{r} 82 \mathrm{I}$, pronuncia algumas palavras mais do que proféticas; ${ }^{8}$ elas são um testamento político e, por isso mesmo, uma abdicação prévia.

No ano seguinte, funda-se o Império Brasileiro, que viveu os seus primeiros dez anos numa atmosfera revolucionária, para ser, afinal, no meio século que se segue, o maior exemplo de democracia política na América do Sul. As diferenças de personalidade entre D. Pedro I e D. Pedro II podem explicar, por uma parte, êsses contrastes. Mas, a meu ver, o que sobretudo os explica é o rápido amadurecimento da nação. $\bar{E}$ verdade que, dominados pelo "formalismo", que é um dos traços psicológicos mais evidentes herdados dos Portuguêses, os Brasileiros contentaram-se com possuir um Parlamento que nada ficava devendo às instituições inglêsas, enquanto descuravam a tarefa de explorar e desenvolver as possibilidades materiais do país. Se Portugal, a partir do século $\mathrm{I}_{7}$, coloca-se deliberadamente fora da civilização intelectual do Ocidente, o Brasil vai se colocar, no século I9, fora da sua civilização material. $\overrightarrow{\mathrm{E}}$ que, antes de mais nada, e para citar ainda uma vez o Professor Fernando de Azevedo,

a estrutura social e econômica... permanecia quase a mesma, baseada ainda na monocultura latifundiária que tetardou a divisão da grande propriedade $e$, portanto, a democratização da terra...9

: "Pedro", dizia êle ao filho, que permanecia no Brasil na qualidade de Príncipe Regente, "põe a coroa na tua cabeça antes que algum aventureiro lance mão dela".

9 Op. cit., p. 171. 
Mas, isso foi assim justamente porque um dos traços da psicologia brasileira é a inclinação humanística do nosso espírito, legado dos Portuguêses consideràvelmente fortalecido não sòmente no período colonial, por fôtça da educação jesuítica, mas ao longo de tôda a história do Brasil. Muitos observadores - e ninguém encara o Brasil com mais espírito crítico do que os próprios Brasileiros - já têm observado que isso se prende a

alguns dos maiores defeitos de nossa cultura, - a tendência excessivamente literária, o gôsto da erudição pela erudição, o pendor ou a resignação fácil às elegâncias superficiais do academismo, o desinterêsse pélas ciências experimentais, a indiferença pelas questões técnicas, e ainda o divórcio entre o povo e os criadores intelectuais, na política, na literatura e nas artes. ${ }^{10}$

Coloque-se um povo com essa psicologia num século que foi eminentemente técnico - o verdadeiro século da Revolução Industrial, porque foi nêle que a Revolução Industrial começou a produzir os seus efeitos- c scrá fácil compreender a espécie de neutralidade com que o Império Brasileito encarou todo progresso material, ao mesmo tempo em que se encontrava na primeira linha de todo o progresso intelectual da época. Aqui, realmente, falhara a let do movimanto que vimos obser'vando como uma das constantes da história brasileira: visto em conjunto, o período monárquico nos parece, pelo menos até os seus últimos vinte anos, como uma fase de incompreensivel paralisia, na qual os brilhantes debates sôbre os problemas substituia os gestos simples ou penosos que poderiam resolvê-los. No fim do Império, as guerras platinas recolocam de maneira imperiosa o problema das suas fronteiras vivas e da sua concurrência vital com outros povos: a República nasce diretamente da Guerra do Paraguai, pois há todo um processo de inquietação política que coincide com o fim da campanha, com a idade avançada do Imperador e com eventualidade da sua sucessão. O Manifesto Republicano data, no Brasil, de I870; vinte anos depois, proclamava-se a República, ainda sôbre o calor fumegante da Abolição.

A partir de $\mathrm{x} 888$, isto é, com o fim da escravatura, a história brasileira retoma o seu movimento característico. A introdução do trabalho livre favorece o extraordinário desenvolvimento da lavoura cafeeira; o extraordinário desenvolvimento da lavoura cafeeira vai provocar o aparecimento e a expansão das atividades industriais. Em certo sentido, a República foi, política, social e materialmente, uma "corrida contra

i10 Fernando de Azevedo, op. cit., III, p. 222. 
o relógio": tratava-se de recuperar o tempo perdido e de colocar o Brasil no ritmo da civilização do século 20. Assim se explicam as inquietações políticas da época: entre 1920 e 1930, o Brasil vive um período de sucessivas revoltas militares, que constatavam o envelhecimento prematuro de uma República feita à imagem das repúblicas do século anterior e prenunciavam a necessidade de uma profunda reforma nas instituições. O processo de reforma terá início com a Revolução de I930, que colocou Getúlio Vargas no poder.

Getúlio Vargas é o grande enigma brasileiro; é forçoso confessar que nós ainda não soubemos decifrá-lo. Seja como fôr, a Revolução de I930, iniciada no meio das maiores esperanças de uma verdadeira democracia, terminaria numa forma de govêrno totalitário da direita (ou da esquerda, como pensam, em nossos dias, os grupos chamados "nacionalistas"...), inspirado claramente nos programas fascistas europeus. Realmente, no mesmo momento em que o Brasil pode pensar, afinal, na construção de um govêrno democrático, as nações européias comcçam a destruir as democracias que possuiam; dessa forma, a Constituição de r934, que foi a forma jurídica tomada pela Revolução de I930, já vinha fortemente tingida de côres corporativas; três anos depois, o Estado Niôvo recolvia assumir claramente a sua posição de ditadura constitucional.

O resto é história contemporânea, em que participamos demais para que nos seja possível interpretá-la. Digamos que Getúlio Vargas governou no campo totalitário enquanto foi possível, isto é, até um momento bastante avançado da guerra; forçado pela opinião pública que, apesar de tudo e ao contrário do que pensam muitos políticos brasileiros, é substancialmente democrática, o govêrno terminaria o conflito ao lado dos Aliados.

Já então um nôvo clima político se instituia: Getúlio Vargas é forçado a deixar o poder, para voltar cinco anos depois, como Presidente eleito. Essa história acidentada termina como uma tragédia grega: num gesto que em grande parte o redime, que confundiu inclusive os seus adversários e que bem pode ter sido a sua última astúcia, Getúlio Vargas entraria definitivamente na posteridade pela porta sangrenta 'do suicidio. Era o fim de um periodo; mas a vida brasileira, que tinha tido em Getúlio Vargas um dos instigadores da "marcha para Oeste", isto é, da conquista efetiva do território, continuaria depois dêle o mesmo movimento incoercível. Assim, o século 20 retoma o mesmo impulso

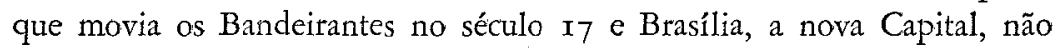
é mais, no domínio das idéias, do que uma tentativa de pôt o Estado e a Sociedade lá onde os Brasileiros, três séculos antes, haviam apenas 
estabelecido a posse da terra. A chamada "política de desenvolvimento", que tem sido, nestes últimos anos, uma espécie de princípio místico do pensamento político no Brasil, não é mais do que uma outra forma daquela recuperação do tempo perdido. Os Brasileiros sentem que ainda não conquistaram o seu lugar de grande potência, um lugar a que, segundo se pode pensar, tudo os destina. Evidentemente, há diversas maneiras de encarar e de promover o desenvolvimento; no fundo, essa palavra não diz nada, e só dirá alguma coisa (dizendo, então, coisas diferentes) conforme o conteúdo que lhe dermos. O "desenvolvimento" será, assim, o nome moderno para o movimento que é a forma brasileira de existir. Também no Brasil existe, por conseqüência, a consciência das "novas fronteiras" e da "grande sociedade": se já sabemos, teòticamente, onde situá-las, ainda discordamos a respeito dos meios que nos podem conduzir ràpidamente até lá. Ràpidamentle - porque, nessa história de movimento, o Tempo é o factor mais importante e o deus vingativo que pode castigar-nos.

WiLison Martins

New York University. 